\title{
The Multiple Stakeholder Approach to Real-world Evidence Generation: the Results of the Jandhyala Method in Observing Expert Consensus on Quality Indicators of Rare Disease Patient Registries (RDRs) by Stakeholder Group
}

Ravi Jandhyala ( $\square$ ravi@medialis.co.uk)

\section{Research}

Keywords: Real-world evidence, rare disease patient registries, quality indicators, pharma stakeholders, non-pharma stakeholders, Jandhyala method, consensus of expert opinion, multiple stakeholder approach

Posted Date: August 6th, 2020

DOl: https://doi.org/10.21203/rs.3.rs-53391/v1

License: (c) (i) This work is licensed under a Creative Commons Attribution 4.0 International License. Read Full License 


\section{Abstract}

\section{Background:}

Evidence is valuable to inform decision making. Understanding stakeholder needs from the evidence of key stakeholders is empirically important to those involved in its generation. Where multiple stakeholders exist, an understanding of whether their questions are homogenous or heterogenous necessitates a dedicated approach that will be of value to those invested in the outcomes of their decisions.

The pharmaceutical industry engages with non-pharmaceutical industry stakeholders: Payors, Prescribers and, under carefully controlled circumstances, patients when commercialising its medicines. This original research focussed on the differences between these groups and their pharma aligned stakeholders: Regulatory Affairs, Market Access, Commercial and Medical Affairs using measures of their common quality indicators (QIs) from rare disease patient registries.

QIs were solicited using the Jandhyala method for observing item awareness and consensus from list generating questioning. They were compared for homogeneity between individual stakeholder groups and the combined pharma and non-pharma stakeholder group population.

\section{Results:}

All stakeholder groups were unique and suggested items peculiar to their own group.

One hundred and eleven discrete QIs were identified: Commercial (8/111; 7.21\%), Market Access (6/111; $5.41 \%)$, Medical Affairs (4/111;3.60\%), Regulatory Affairs (6/111; 5.41\%), Patients $(14 / 111 ; 12.61 \%)$, Payors $(6 / 111 ; 5.41 \%)$, and Prescribers $(9 / 111 ; 8.11 \%)$. Each stakeholder's proportion of unique Qls to the total was not statistically significant to the group as a whole.

Non-pharma stakeholders generated 29/111 (26.13\%) unique QIs, while pharma stakeholders generated 24/111 (21.62\%). The total unique Qls across both stakeholder groups were 53/111 (47.75\%). Two Qls were unanimously suggested and agreed upon by all stakeholder groups $(7 / 7 ; 100 \%)$ : 'Engages with patients and gains their buy-in' and 'Includes a core data set as part of outcomes'.

There was homogeneity in consensus on common Qls between Commercial - Market Access $(P=0.006)$, Market Access - Regulators $(P=0.006)$, Commercial - Prescribers $(P=0.001)$, Market Access - Prescribers $(P=0.033)$, and Commercial - Medical Affairs $(P=0.020)$.

\section{Conclusions:}

There is sufficient evidence to support a multiple stakeholder approach for generating real-world evidence. There was a mismatch between pharma and non-pharma stakeholders of $47.75 \%$ indicating redundancies of QIs on each side of this divide. Patients and Payor (non-pharma) groups have been highlighted for greater alignment with pharma stakeholder groups. 


\section{Introduction}

Evidence is the product of research being conducted to answer a particular research question. Such evidence is of the greatest value to its 'consumers', who are defined by the relevance of the research question as it pertains to them, including the value that the answers will have to them in decision making (1). Evidence-based decision making can be assumed as a risk-mitigating approach by some (2); thus, consumers of evidence may fall into groups on the basis of their common unanswered research questions and the effect that the evidence targeted to answering it is expected to have on an environment.

Consumers may generate relevant evidence themselves or have it generated for them by another interested party. This party may be driven by the shared benefits, to themselves and to the consumer, of answering a specific set of consumer-relevant questions.

The pharmaceutical industry is one such interested party which manufactures medicines for the benefit of patients in return for revenue generated by its adoption (3). However, key hurdles of regulatory approval, reimbursement and prescribing practices need to be addressed, with evidence, tailored to their gatekeeper consumer's needs before these benefits can be broadly realised.

It has been argued that these gatekeepers, more constructively termed 'stakeholders', require a dedicated strategy to meet their evidence needs. Furthermore, where more than one need exists, such as in the pharmaceutical industry, a multiple stakeholder approach is required to plan and deliver evidence that maximises the return on investment, in the form of time and resources, by ensuring as many stakeholders can benefit from the generated evidence as possible (4).

Patient registries, or observational cohort clinical studies or prospective and/or retrospective type, have the potential to generate answers to a large number of research questions in real-world patients (5), primarily if these questions are appropriately understood and incorporated in the planning phase $(6,7)$. Their value can be amplified in rare diseases where small, discrete patient populations can be combined and studied as a larger, single population to increase the quality of the evidence generated. Orphan medicines are also among the more costly drugs and are arguably under greater scrutiny because of this (8). Therefore, the impact of well-targeted evidence supporting the approval, reimbursement, and prescribing of orphan medicines to encourage their adoption, offers the best opportunity for rare populations to receive this life-changing treatment.

The pharmaceutical industry has evolved by recognising the need to engage with key non-pharma (PH-) stakeholders such as the Regulator, Payor (Payo), Patient (Pati) and Prescriber (Pres) by aligning their internal functions to mirror the needs of these stakeholders to ensure their perspective remains in focus for the company $(9,10)$. This could be done using functions such as Regulatory Affairs (RAff), Market Access (MAcc), Commercial (Comm) and Medical Affairs (MAff). Several companies have also implemented patient advocacy functions to engage with these $\mathrm{PH}$-stakeholders. 
Given the value and versatility of patient registries in rare diseases for generating real-world evidence (RWE) and the importance of the decisions made by the various stakeholders involved in making new medicines available (11), three clear questions have been identified as the subject of this work:

Firstly, whether a multiple stakeholder approach is required by confirming the differences in the stakeholder needs between them. If so, the second question regarding what the exact nature of the differences are and the level of agreement on any common items across the groups should be posed. Thirdly, whether pharma is aligned with $\mathrm{PH}$ - stakeholders or not and if there is an alignment between the individual stakeholder groups, especially between those Pharma $(\mathrm{PH}+)$ stakeholder groups intended to mirror specific $\mathrm{PH}$ - stakeholder groups.

To answer these questions alignment will be measured by comparing the detailed lists of quality indicators (QIs) of rare disease patient registries (RDRs), solicited by the Jandhyala method, to observe consensus among the stakeholder groups on items that should be included.

It is hoped that outputs from this work may help to inform the planning of RWE generating strategies, and if a multiple stakeholder approach is justified.

\section{Methods}

\section{Jandhyala Method}

This study was conducted using the Jandhyala method (12), a novel mixed-methods approach for generating expert opinion. Expert opinion is generated by observing levels of awareness and consensus relating to items identified from list-generating questioning via two anonymised online surveys and calculating an awareness index (Al) and consensus index $(\mathrm{Cl})$ for each item, respectively (13). The objective of this study was to identify the QIs for a successful RDR from the perspective of multiple relevant stakeholders, or consumers, of the resulting evidence, as well as assess the heterogeneity among stakeholders' expert opinions on the QIs needed for a successful RDR. There were no formal endpoints in this study, as the outcomes were consensus on items that indicated successful RDR quality.

During the first Awareness Round (1) survey, participants were asked to respond to the list-generating question: "What is important to planning for, or judging the success of, a Rare Disease Registry?"They were asked to provide a minimum of three, and a maximum of ten, free-text answers.

The participants' responses from this Awareness Round (1) were analysed per group and refined into mutually exclusive items by three investigators using a process of content analysis and open coding. The codes were then attributed to the relevant participants' answers by one investigator, before being confirmed with a second.

The participants who completed the first round were asked to participate in the second Consensus Round (2) survey, and were asked to rate their level of agreement with the inclusion of the items arising from the 
Awareness Round (1) survey in the list of Qls using a five-point Likert-scale (strongly agree; agree; neither agree nor disagree; disagree; or strongly disagree). Items reaching a consensus level of $\geq 50 \%$ (consensus index $\geq 0.5$ ) were retained in the final list.

\section{Study Participants}

Participants were invited from the author's professional network and via advertisements placed on professional social media networking sites based on experience in RWE in rare diseases from the following industry and non-industry stakeholder groups: MAff, MAcc, Comm, RAff, Pati, Pres and Payo.

\section{Study Variables}

In line with the published method and its reporting convention, the Awareness Index (Al), Consensus Index $(\mathrm{Cl})$, and an Index score, indicating prompting, were calculated for each generated item within their stakeholder group.

The Al, measured in the Awareness Round (1), was calculated using the frequency of an item concerning the most frequently occurring item. The minimal awareness threshold was defined as an Awareness Index $\geq 50 \%$. The $\mathrm{Cl}$ was calculated as the percentage of participants who agreed or strongly agreed with an item in the Consensus Round (2).

The Index score measured whether prompting occurred during the Consensus Round (2). Prompting occurred if the absolute difference between the $\mathrm{Al}$ and the $\mathrm{Cl}$ was $\geq 0.05$ (or $5 \%$ ). Prompting was considered negligible if the absolute difference was $\leq 0.05$ (or $5 \%$ ). Unprompted consensus occurred when most participants suggested an item in the Awareness Round (1), and the majority agreed, or strongly agreed, that the item was important in the Consensus Round (2). Any item that was not suggested by the participants during the Awareness Round (1), but which was agreed to be important in the Consensus Round (2), was prompted completely. Items achieving a $\mathrm{Cl} \geq 0.51$ were retained.

The different stakeholder groups were recruited at different time points; thus, it was necessary to code the Awareness Round (1) data for each group individually to send the Consensus Round (2) survey out timeously. Consequently, the generated items could not be harmonised across all groups until the end of the data collection period, and an additional round of analysis was carried out to standardise the generated items and avoid repetition.

The list of QIs for a successful registry from the perspective of multiple stakeholders was generated from the expert opinion survey.

\section{Statistical Analysis}

\section{Absolute heterogeneity in stakeholder responses (Table 1)}

The threshold for absolute heterogeneity of a stakeholder group was the generation of at least one unique QI. The number of unique QIs generated by each stakeholder group, the total number of items 
generated by each stakeholder group, and the proportion of unique items is presented.

A Chi-squared test was performed to see whether the proportion of unique QIs generated by each stakeholder group was significantly different than those of others (combined) using two proportions tests. A P-value $\leq 0.05$ indicated that the proportion of unique Qls generated by the stakeholder group is significantly different (heterogeneous) than that of others.

\section{Relative heterogeneity (Table 2)}


Table 2

Generated items that reached consensus in four or more stakeholder groups (SHGs).

\begin{tabular}{|c|c|c|c|c|c|c|}
\hline Item & Title & $\begin{array}{l}\text { SHG } \\
\text { item } \\
\text { aware }\end{array}$ & $\begin{array}{l}\text { SHG } \\
\mathrm{Cl} \leq 2 \\
\text { on } \\
\text { item }\end{array}$ & $\begin{array}{l}\text { Items } \\
\mathrm{Cl} \geq \\
0.05 \\
(\%)\end{array}$ & $\begin{array}{l}\text { Overall } \\
\text { Heterogeneity } \\
\text { (P-value) }\end{array}$ & $\begin{array}{l}\text { PH-vs. PH+ } \\
\text { heterogeneity } \\
\text { (P-value) }\end{array}$ \\
\hline 28 & $\begin{array}{l}\text { Engages with patients } \\
\text { (organisations) and gains } \\
\text { their buy-in }\end{array}$ & 7 & 7 & 100 & 0.347 & 0.999 \\
\hline 41 & $\begin{array}{l}\text { Includes a core data set as } \\
\text { part of outcomes }\end{array}$ & 7 & 7 & 100 & 0.475 & 0.502 \\
\hline 2 & $\begin{array}{l}\text { Collects patient relevant } \\
\text { [reported] outcomes } \\
\text { [symptoms] }\end{array}$ & 6 & 5 & 83 & $0.022^{\star}$ & 0.152 \\
\hline 19 & $\begin{array}{l}\text { Implements data } \\
\text { management procedures } \\
\text { (edit checks for accuracy) }\end{array}$ & 6 & 5 & 83 & 0.118 & $0.044^{*}$ \\
\hline 25 & $\begin{array}{l}\text { Reflects clear rationale and } \\
\text { objectives in its design }\end{array}$ & 6 & 6 & 100 & $0.029 *$ & 0.602 \\
\hline 30 & $\begin{array}{l}\text { Engages with prescribers and } \\
\text { gains their buy-in }\end{array}$ & 6 & 6 & 100 & $0.031^{*}$ & 0.496 \\
\hline 32 & $\begin{array}{l}\text { Utilises data entry forms that } \\
\text { at easy to use }\end{array}$ & 6 & 6 & 100 & 0.401 & 0.949 \\
\hline 4 & $\begin{array}{l}\text { Collects data on quality of } \\
\text { life }\end{array}$ & 5 & 4 & 80 & $0.015^{\star}$ & 0.500 \\
\hline 7 & $\begin{array}{l}\text { Collects information on all } \\
\text { available treatments }\end{array}$ & 5 & 4 & 80 & $0.022^{*}$ & $0.03^{*}$ \\
\hline 12 & $\begin{array}{l}\text { Allows sites to access their } \\
\text { own data }\end{array}$ & 5 & 5 & 100 & 0.381 & 0.446 \\
\hline 13 & $\begin{array}{l}\text { Maximises recruitment of an } \\
\text { eligible patient population of } \\
\text { interest }\end{array}$ & 5 & 5 & 100 & 0.205 & 0.839 \\
\hline 20 & $\begin{array}{l}\text { Implements data quality } \\
\text { procedures (completeness) }\end{array}$ & 5 & 4 & 80 & 0.059 & 0.786 \\
\hline 35 & $\begin{array}{l}\text { Engages with regulators and } \\
\text { gains their buy-in }\end{array}$ & 5 & 5 & 100 & 0.267 & 0.377 \\
\hline
\end{tabular}

$*=$ items meeting consensus of $50 \%(\mathrm{Cl} \geq 0.50)$ across all stakeholder groups for inclusion in list
quality indicators of rare disease patient registries.

Comm (Commercial); MAcc (Market Access); MAff (Medical Affairs); RAff (Regulatory Affairs); Pati (Patients); Payo (Payors); Pres (Prescribers) 


\begin{tabular}{|c|c|c|c|c|c|c|}
\hline Item & Title & $\begin{array}{l}\text { SHG } \\
\text { item } \\
\text { aware }\end{array}$ & $\begin{array}{l}\text { SHG } \\
\mathrm{Cl} \leq 2 \\
\text { on } \\
\text { item }\end{array}$ & $\begin{array}{l}\text { Items } \\
\mathrm{Cl} \geq \\
0.05 \\
(\%)\end{array}$ & $\begin{array}{l}\text { Overall } \\
\text { Heterogeneity } \\
\text { (P-value) }\end{array}$ & $\begin{array}{l}\text { PH-vs. PH+ } \\
\text { heterogeneity } \\
\text { (P-value) }\end{array}$ \\
\hline 36 & $\begin{array}{l}\text { Engages with payors and } \\
\text { gains their buy-in }\end{array}$ & 5 & 5 & 100 & 0.267 & 0.377 \\
\hline 48 & $\begin{array}{l}\text { Declares sponsorship in a } \\
\text { clear and transparent manner }\end{array}$ & 5 & 3 & 60 & $0.006^{\star}$ & $0.014^{\star}$ \\
\hline 10 & $\begin{array}{l}\text { Generates a large number of } \\
\text { publications }\end{array}$ & 4 & 3 & 75 & 0.061 & 0.097 \\
\hline 14 & $\begin{array}{l}\text { Achieves a representative } \\
\text { demographic of the } \\
\text { population of interest }\end{array}$ & 4 & 4 & 100 & 0.083 & 0.230 \\
\hline 22 & $\begin{array}{l}\text { Sponsor funds provides } \\
\text { appropriate level of funding }\end{array}$ & 4 & 3 & 75 & 0.149 & 0.305 \\
\hline 26 & Offers site-specific support & 4 & 4 & 100 & 0.218 & 0.198 \\
\hline 34 & $\begin{array}{l}\text { Utilises online electronic data } \\
\text { capture tool }\end{array}$ & 4 & 4 & 100 & 0.092 & 0.232 \\
\hline 49 & $\begin{array}{l}\text { Allows patients to access } \\
\text { their own data }\end{array}$ & 4 & 4 & 100 & 0.364 & 0.172 \\
\hline 52 & $\begin{array}{l}\text { Reports on data quality } \\
\text { (completeness) }\end{array}$ & 4 & 4 & 100 & 0.124 & 0.289 \\
\hline 56 & $\begin{array}{l}\text { Incorporates clear and } \\
\text { transparent governance } \\
\text { processes }\end{array}$ & 4 & 3 & 75 & $0.019 *$ & 0.283 \\
\hline \multicolumn{7}{|c|}{$\begin{array}{l}*=\text { items meeting consensus of } 50 \%(\mathrm{Cl} \geq 0.50) \text { across all stakeholder groups for inclusion in list } \\
\text { quality indicators of rare disease patient registries. }\end{array}$} \\
\hline $\begin{array}{l}\text { Comr } \\
\text { (Patie }\end{array}$ & $\begin{array}{l}\text { Commercial); MAcc (Market A } \\
\text { s); Payo (Payors); Pres (Prescl }\end{array}$ & $\begin{array}{l}\text { ss); } \mathrm{M} \\
\text { s) }\end{array}$ & (Med & ffairs & ff (Regulato & fairs); Pati \\
\hline
\end{tabular}

The heterogeneity among stakeholders for each item was examined using individual- or expert-level consensus scores. For this analysis, the consensus scores of the individual stakeholders were further classified as agree (expert-level consensus score of 4 or 5 in the Jandhyala method) and disagree (expertlevel consensus score of 1 to 3 in the Jandhyala method). For each item, these classified scores were tabulated among the stakeholder groups that provided consensus scores for the item. Chi-square tests were performed on the tabulated data, and a P-value $\leq 0.05$ indicated heterogeneity among stakeholders for consensus scoring on the item.

The stakeholder groups were combined into PH+; Comm, MAcc, MAff, and Regulators; and PH; Pati, Pres, and Payo. Chi-square testing was also performed on the combined tabulated data and a P-value $\leq 0.05$ indicated heterogeneity in consensus on each item between the $\mathrm{PH}+$ and $\mathrm{PH}$ - stakeholders for the item. 
Heterogeneity in common pairwise stakeholder items

(Table 3) 
Table 3

Pairwise analysis of stakeholder groups on the heterogeneity of consensus indices for common items (heterogeneity: $\mathrm{P} \geq 0.05$ ).

\begin{tabular}{|c|c|c|c|c|}
\hline Pairs & $\begin{array}{l}\text { Number of } \\
\text { Common Items }\end{array}$ & $\begin{array}{l}\text { Total Number of } \\
\text { Items in Pair }\end{array}$ & $\begin{array}{l}\text { Common/ Total Items in } \\
\text { Pair (\%) }\end{array}$ & P-Value \\
\hline $\begin{array}{l}\text { Comm - } \\
\text { MAcc }\end{array}$ & 20 & 76 & 26.32 & $0.006^{\star}$ \\
\hline $\begin{array}{l}\text { MAcc - } \\
\text { RAff }\end{array}$ & 19 & 66 & 28.79 & $0.006^{*}$ \\
\hline $\begin{array}{l}\text { Pati- } \\
\text { RAff }\end{array}$ & 19 & 86 & 22.09 & 0.198 \\
\hline $\begin{array}{l}\text { Comm - } \\
\text { Pres }\end{array}$ & 17 & 76 & 22.37 & $0.0006^{*}$ \\
\hline $\begin{array}{l}\text { Comm - } \\
\text { Pati }\end{array}$ & 16 & 73 & 21.92 & 0.827 \\
\hline $\begin{array}{l}\text { Comm - } \\
\text { Payo }\end{array}$ & 16 & 78 & 20.51 & 0.438 \\
\hline $\begin{array}{l}\text { Comm - } \\
\text { RAff }\end{array}$ & 16 & 60 & 26.67 & 0.109 \\
\hline $\begin{array}{l}\text { MAcc - } \\
\text { Pres }\end{array}$ & 16 & 80 & 20.00 & $0.033^{\star}$ \\
\hline $\begin{array}{l}\text { Payo - } \\
\text { RAff }\end{array}$ & 16 & 67 & 23.88 & 0.056 \\
\hline $\begin{array}{l}\text { Pres - } \\
\text { RAff }\end{array}$ & 16 & 70 & 22.86 & 0.152 \\
\hline $\begin{array}{l}\text { Comm - } \\
\text { MAff }\end{array}$ & 15 & 72 & 20.83 & $0.02^{\star}$ \\
\hline Pati - Pres & 15 & 70 & 21.43 & 0.785 \\
\hline $\begin{array}{l}\text { MAcc - } \\
\text { Payo }\end{array}$ & 13 & 57 & 22.81 & 0.277 \\
\hline $\begin{array}{l}\text { Pati - } \\
\text { Payo }\end{array}$ & 13 & 60 & 21.67 & 0.520 \\
\hline $\begin{array}{l}\text { MAcc- } \\
\text { MAff }\end{array}$ & 12 & 62 & 19.35 & 0.077 \\
\hline $\begin{array}{l}\text { MAcc - } \\
\text { Pati }\end{array}$ & 12 & 77 & 15.58 & 0.639 \\
\hline $\begin{array}{l}\text { Payo - } \\
\text { Pres }\end{array}$ & 12 & 80 & 15.00 & 0.376 \\
\hline
\end{tabular}




\begin{tabular}{|c|c|c|c|c|}
\hline Pairs & $\begin{array}{l}\text { Number of } \\
\text { Common Items }\end{array}$ & $\begin{array}{l}\text { Total Number of } \\
\text { Items in Pair }\end{array}$ & $\begin{array}{l}\text { Common/ Total Items in } \\
\text { Pair (\%) }\end{array}$ & P-Value \\
\hline $\begin{array}{l}\text { MAff - } \\
\text { Pres }\end{array}$ & 11 & 82 & 13.41 & 0.172 \\
\hline $\begin{array}{l}\text { MAff - } \\
\text { Pati }\end{array}$ & 10 & 67 & 14.93 & 0.633 \\
\hline $\begin{array}{l}\text { MAff - } \\
\text { RAff }\end{array}$ & 10 & 69 & 14.49 & 0.187 \\
\hline $\begin{array}{l}\text { MAff - } \\
\text { Payo }\end{array}$ & 8 & 72 & 11.11 & 0.883 \\
\hline $\mathrm{PH}+-\mathrm{PH}-$ & 46 & 111 & 41.44 & $0.00001 *$ \\
\hline \multicolumn{5}{|c|}{$\begin{array}{l}*=\text { items meeting consensus of } 50 \%(\mathrm{Cl} \geq 0.50) \text { across all stakeholder groups for inclusion in list QIs } \\
\text { of rare disease patient registries. }\end{array}$} \\
\hline \multicolumn{5}{|c|}{$\begin{array}{l}\text { Comm (Commercial); MAcc (Market Access); MAff (Medical Affairs); RAff (Regulatory Affairs); Pati } \\
\text { (Patients); Payo (Payors); Pres (Prescribers) }\end{array}$} \\
\hline \multicolumn{5}{|c|}{ ADDITIONAL FILES } \\
\hline \multicolumn{5}{|c|}{ Supplementary Information 1} \\
\hline \multicolumn{5}{|c|}{ DOC (Microsoft Word) } \\
\hline \multicolumn{5}{|c|}{$\begin{array}{l}\text { Supplementary Information Depicting Awareness Round (1) and Consensus Round (2) Results } \\
\text { Regarding Items/Quality Indicators that Pharma Stakeholders Believe Should Constitute Rare Disease } \\
\text { Patient Registries (RDRs). }\end{array}$} \\
\hline \multicolumn{5}{|c|}{ Data includes two tables and one figure } \\
\hline \multicolumn{5}{|c|}{ Supplementary Information 2} \\
\hline \multicolumn{5}{|c|}{ DOC (Microsoft Word) } \\
\hline \multicolumn{5}{|c|}{$\begin{array}{l}\text { Supplementary Information Depicting Awareness Round (1) and Consensus Round (2) Results } \\
\text { Regarding Items/Quality Indicators that Non-Pharma Stakeholders Believe Should Constitute Rare } \\
\text { Disease Patient Registries (RDRs). }\end{array}$} \\
\hline \multicolumn{5}{|c|}{ Data Includes two tables and one figure } \\
\hline
\end{tabular}

The heterogeneity between stakeholder pairs for the list of items generated and consented upon by each stakeholder group within the pairs were examined. This analysis used item-level data and the stakeholder group-level consensus score per item based on the Jandhyala method, ranging from 1 to 4 . These scores were categorised according to the method's published scheme into Complete consensus, Consensus +, Consensus - and No consensus, numbered 1,2,3,4, respectively. The category numbers for each generated list of items are tabulated between each stakeholder pair. Chi-square tests were performed on the tabulated data, and a P-value $\leq 0.05$ indicated homogeneity between the stakeholder pair in their consensus on the item. 


\section{Results}

\section{Study Participants}

Recruitment took place in May 2019 and January 2020. A total of 55 participants were recruited. PHstakeholder participants were made up of 9 Pres, 7 Payo and 7 Pati. PH + stakeholder participants comprised: 13 MAff, 5 MAcc, 7 Comm and 5 RAff. Non-industry regulatory functions were uniformly unable to participate in the study on the grounds of conflict of interest. Due to recruitment difficulties, the RAff experts were not always specialised in rare disease, and some Payo (1/7) had to be recruited from outside the EU.

\section{Jandhyala Method}

When using the Jandhyala Method, stakeholder populations were considered homogenous in their specific requirements from RWE if the overall heterogeneous P-value was $\leq 0.05$. Conversely, stakeholder populations were deemed heterogenous to their specific requirements from RWE if the overall homogenous P-value was $\geq 0.05$.

\section{Statistical Analysis}

\section{Heterogeneity in Stakeholder Group QIs}

\section{Absolute Heterogeneity}

Responses to Awareness Round (1) Survey

From the Awareness Round (1) survey, 111 discrete items were generated and received an $\mathrm{Al}$ and a $\mathrm{Cl}$ (Supplements 1 and 2). Comm (8/111; 7.21\%), MAcc (6/111; 5.41\%), MAff (4/111; 3.60\%), RAff (6/111; $5.41 \%)$, Pati $(14 / 111 ; 12.61 \%)$, Payo $(6 / 111 ; 5.41 \%)$ and Pres $(9 / 111 ; 8.11 \%)$ all contributed unique itemst (Table 1 and Fig. 1). All stakeholder groups met the threshold for absolute heterogeneity within the overall stakeholder group result.

In total, the PH + group generated 30/55 (54.55\%) unique/total items: Comm (8/41; 19.51\%), MAcc (6/35; 17.14\%), MAff (4/25; 16.00\%) and RAff (6/37; 16.22\%) (Table 1 and Fig. 1$)$.

$\mathrm{PH}$ - stakeholders generated 29/111 (26.13\%) unique QIs and PH + stakeholders generated 24/111 (21.62\%) unique QIs. The total of unique QIs, across $\mathrm{PH}+$ and $\mathrm{PH}$ - stakeholder groups was 53/111 (47.75\%) (Table 1 and Fig. 1).

Relative Heterogeneity 
The mean of unique items suggested per stakeholder group was 7.57, whereas the mean of total items suggested was 35.71 . The mean stakeholder group size was 7.86 participants per stakeholder group. The Pati stakeholder group suggested both the largest number of unique and total items $14 / 45(31.11 \%, P=$ 0.111). The MAff stakeholder group was the largest group (13/55) but suggested the smallest number of unique and total items: $4 / 25(16.00 \%, P=0.680)$. The proportion of unique to total number of items for Comm, Macc, Raff, Pati, Payo and Pres were: 8/41 (19.51\%, P = 0.936), 6/35 (17.14\%, P = 0753), 6/37 $(16.22 \%, P=0.558), 6 / 32(18.75 \%, P=0.895)$ and $9 / 35(25.71 \%, P=0.059)$, respectively (Table 1 and Fig. 1). All stakeholder groups were found to be equally unique within the group in their proportion of suggested unique to indicators.

Table 1

Number of unique items suggested by stakeholder groups as a proportion of the total.

\begin{tabular}{|c|c|c|c|c|c|c|c|}
\hline & Stakeholder & $\begin{array}{l}\text { Group } \\
\text { size }\end{array}$ & $\begin{array}{l}\text { Unique } \\
\text { Suggested } \\
\text { Items }\end{array}$ & $\begin{array}{l}\text { Total Items } \\
\text { Suggested }\end{array}$ & $\begin{array}{l}\text { Proportion/ } \\
\text { total SH } \\
\text { items }\end{array}$ & $\begin{array}{l}\mathrm{P}- \\
\text { value }\end{array}$ & $\begin{array}{l}\text { Proportion/ } \\
\text { total items }\end{array}$ \\
\hline \multirow[t]{5}{*}{$\mathrm{PH}+$} & Comm & 7 & $8+$ & 41 & $19.51 \%$ & 0.936 & $7.21 \%$ \\
\hline & MAcc & 5 & $6+$ & 35 & $17.14 \%$ & 0.753 & $5.41 \%$ \\
\hline & MAff & 13 & $4 \dagger$ & 25 & $16.00 \%$ & 0.680 & $3.60 \%$ \\
\hline & RAff & 5 & $6+$ & 37 & $16.22 \%$ & 0.558 & $5.41 \%$ \\
\hline & Total & 30 & 24 & 77 * & $31.17 \%$ & NA & $21.62 \%$ \\
\hline \multirow[t]{4}{*}{$\mathrm{PH}-$} & Pati & 9 & $14 \dagger$ & 45 & $31.11 \%$ & 0.111 & $12.61 \%$ \\
\hline & Payo & 7 & $6+$ & 32 & $18.75 \%$ & 0.895 & $5.41 \%$ \\
\hline & Pres & 9 & $9+$ & 35 & $25.71 \%$ & 0.059 & $8.11 \%$ \\
\hline & Total & 25 & 29 & 80 * & $36.25 \%$ & NA & $26.13 \%$ \\
\hline \multirow{2}{*}{$\begin{array}{l}\text { Overall } \\
(\mathrm{PH}+) \\
+ \\
(\mathrm{PH}-)\end{array}$} & Total & 55 & 53 & 111 * & $47.75 \%$ & NA & $47.75 \%$ \\
\hline & Mean & 7.86 & 7.57 & 35.71 & $20.64 \%$ & NA & $6.82 \%$ \\
\hline
\end{tabular}

Comm (Commercial); MAcc (Market Access); MAff (Medical Affairs); RAff (Regulatory Affairs); Pati (Patients); Payo (Payors); Pres (Prescribers)

† Stakeholder groups meeting the threshold of absolute heterogeneity by suggesting unique items 
Comm (Commercial); MAcc (Market Access); MAff (Medical Affairs); RAff (Regulatory Affairs); Pati (Patients); Payo (Payors); Pres (Prescribers)

\title{
Heterogeneity in Item Consensus
}

\author{
Responses to Consensus Round (2) Survey
}

Sixteen items out of 111 reached consensus (Consensus Index $\leq 2$ ) in four or more groups of stakeholders. Eight items resulted from the division of a generated item into its constituent parts, and eight generated items were merged with other generated items as part of the harmonisation process. A degree of commonality and heterogeneity exists between the consensus levels of these common items.

Two items reached consensus in four or more stakeholder groups for inclusion in list Qls of RDRs: "Includes a core dataset as part of the outcomes" and "Engages with patients (organisations) and gains their buy-in" (Table 2 and Figure 2).

(a) stakeholder: uniqueness, consensus index; (b) heterogeneity of items by level of stakeholder consensus; (c) heterogeneity by Pharma $(\mathrm{PH}+)$ or Non-Pharma $(\mathrm{PH}-)$ stakeholder group consensus threshold for inclusion $(\mathrm{Cl} \geq 0.05)$ within their discipline listed in item numbering ascending order.

\section{Heterogeneity in Pairwise Stakeholder Consensus}

All pairs of stakeholder groups were examined for homogeneity in their unique QIs. Seven stakeholder groups yielded 21 comparisons. 5/21 pairwise comparisons were statistically significant and therefore, homogeneous: Comm - Macc (Table 3 and Figure 2).

\section{Discussion}

This research sought to confirm the presence of discrete stakeholder groups with equally unique needs to validate the need for a multiple stakeholder approach in evidence generation. This was confirmed in both $\mathrm{PH}+$ and $\mathrm{PH}$ - stakeholders. Despite the unique Qls mapped out per stakeholder group, several common indicators existed. An understanding of both common and unique items enables evidence generation to be planned to satisfy the needs of more than one stakeholder, thereby improving return on investment and resource attrition over time. Two QIs of RDRs met with unanimous agreement across the $\mathrm{PH}+$ and $\mathrm{PH}$-stakeholder groups were identified and should be considered 'core' to the success of this type of research: 1) the need to have a core data set and 2) the need to both engage with patients and obtain their buy-in.

The core dataset has clear significance in the context of the 'Achilles heel' of observational clinical studies - that of missing data from the data requested. The issue here is the central requirement that an observational study must not mandate data collection through unnecessary interventions on patients in the real world, but simply observe their standard diagnostic and monitoring practice. The inevitability of missing data and the limitation this places on the quality of the evidence generated is the common theme running through these stakeholders' appreciation for a key QI of a potential powerhouse of evidence 
generation. Development of core datasets in rare diseases is currently an area of interest for the author and work is ongoing on how these can be delivered with the multiple stakeholders in mind.

With reference to the work presented here, it should be recognised that $\mathrm{PH}+$ stakeholders have evolved, in alignment with, and primarily as a result of, the recognition of the various gatekeeper $\mathrm{PH}$ - stakeholder groups above. The results of the dedicated pairwise analysis of common QIs between all possible pairs of stakeholders were surprising. Expected pairs failed to yield homogeneity in unique indicators, most notably Payo - MAcc, where other pairs yielded unexpected and, arguably less useful alignment, such as MAcc - Raff and MAcc - Comm.

The above findings were in the context of a broader and more worrying lack of alignment in homogeneity between the $\mathrm{PH}+$ and $\mathrm{PH}$ - stakeholders; 53/111 (47.75\%) Qls were without a corresponding partner on either side of this divide. Even more worrying was, despite the recognition that patients were unanimously agreed to be a stakeholder group that needed to be engaged with, none of the Patient stakeholder pairwise tests yielded homogeneity in common Qls with any other groups.

The original research presented here provides some evidence which can be used to inform corrective strategies by providing a Neutral List of QIs against which existing patient registries can be measured, and future registries can be designed and implemented. Further work is required to appropriately understand the QIs of the $\mathrm{PH}$ - regulatory group in a similar framework.

\section{Declarations}

\section{Ethics Approval and Consent to Participate}

All participants provided informed consent to participate in this research study, and all ethical standards were adhered to.

\section{Consent for Publication}

Not applicable.

\section{Availability of Data and Materials}

All data generated or analysed during this study are included in this published article and its supplementary information files.

\section{Competing Interests}

The author declares that they have no competing interests.

\section{Funding}

No external funding sources supported this work. 


\section{Authors' Contributions}

$\mathrm{RJ}$ is the sole author of this manuscript.

\section{Acknowledgements}

RJ would like to thank the biostatisticians and medical writers at Medialis Ltd for their statistical and editorial support.

\section{References}

[1] R. Jandhyala, 'Comment on: "Patient Registries: An Underused Resource for Medicines Evaluation: Operational Proposals for Increasing the Use of Patient Registries in Regulatory Assessments"', Drug Saf, vol. 42, no. 12, pp. 1515-1516, Dec. 2019, doi: 10.1007/s40264-019-00862-x.

[2] A.-S. Hiswåls, C. W. Hamrin, Å. Vidman, and G. Macassa, 'Corporate social responsibility and external stakeholders' health and wellbeing: a viewpoint', J Public Health Res, vol. 9, no. 1, Jun. 2020, doi: 10.4081/jphr.2020.1742.

[3] R. C. Brownson et al., 'Evidence-Based Decision Making in Public Health', J Public Health Manag Pract, vol. 5, pp. 86-97, 1999.

[4] A. Szmelter, 'Global Pharmaceutical Industry: Characteristics and Trends', Global Supply Chains in the Pharmaceutical Industry, 2019. www.igi-global.com/chapter/global-pharmaceutical-industry/216205 (accessed Jul. 30, 2020).

[5] A. Boaz, S. Hanney, R. Borst, A. O'Shea, and M. Kok, 'How to engage stakeholders in research: design principles to support improvement', Health Research Policy and Systems, vol. 16, no. 1, p. 60, Jul. 2018, doi: 10.1186/s12961-018-0337-6.

[6] I. Melnikova, 'Rare diseases and orphan drugs', Nat Rev Drug Discov, vol. 11, no. 4, pp. 267-268, Apr. 2012, doi: $10.1038 /$ nrd3654.

[7] R. E. Sherman et al., 'Real-World Evidence - What Is It and What Can It Tell Us?', N Eng/ J Med, vol. 375, no. 23, pp. 2293-2297, Dec. 2016, doi: 10.1056/NEJMsb1609216.

[8] M. Kessel, 'The problems with today's pharmaceutical business-an outsider's view', Nat Biotechnol, vol. 29 , no. 1 , pp. $27-33$, Jan. 2011 , doi: $10.1038 /$ nbt. 1748 .

[9] V. K. Noonan et al., 'The Rick Hansen Spinal Cord Injury Registry (RHSCIR): a national patient-registry', Spinal Cord, vol. 50, no. 1, Art. no. 1, Jan. 2012, doi: 10.1038/sc.2011.109.

[10] S. Wang, P. Verpillat, J. Rassen, A. Patrick, E. Garry, and D. Bartels, 'Transparency and Reproducibility of Observational Cohort Studies Using Large Healthcare Databases.: Transparency and reproducibility in 
healthcare databases', Clin. Pharmacol. Ther., vol. 99, no. 3, pp. 325-332, Mar. 2016, doi: 10.1002/cpt.329.

[11] J. Rycroft-Malone and K. Seers, 'What counts as evidence in evidence-based practice?', Journal of Advanced Nursing, p. 10, 2004.

\section{Figures}




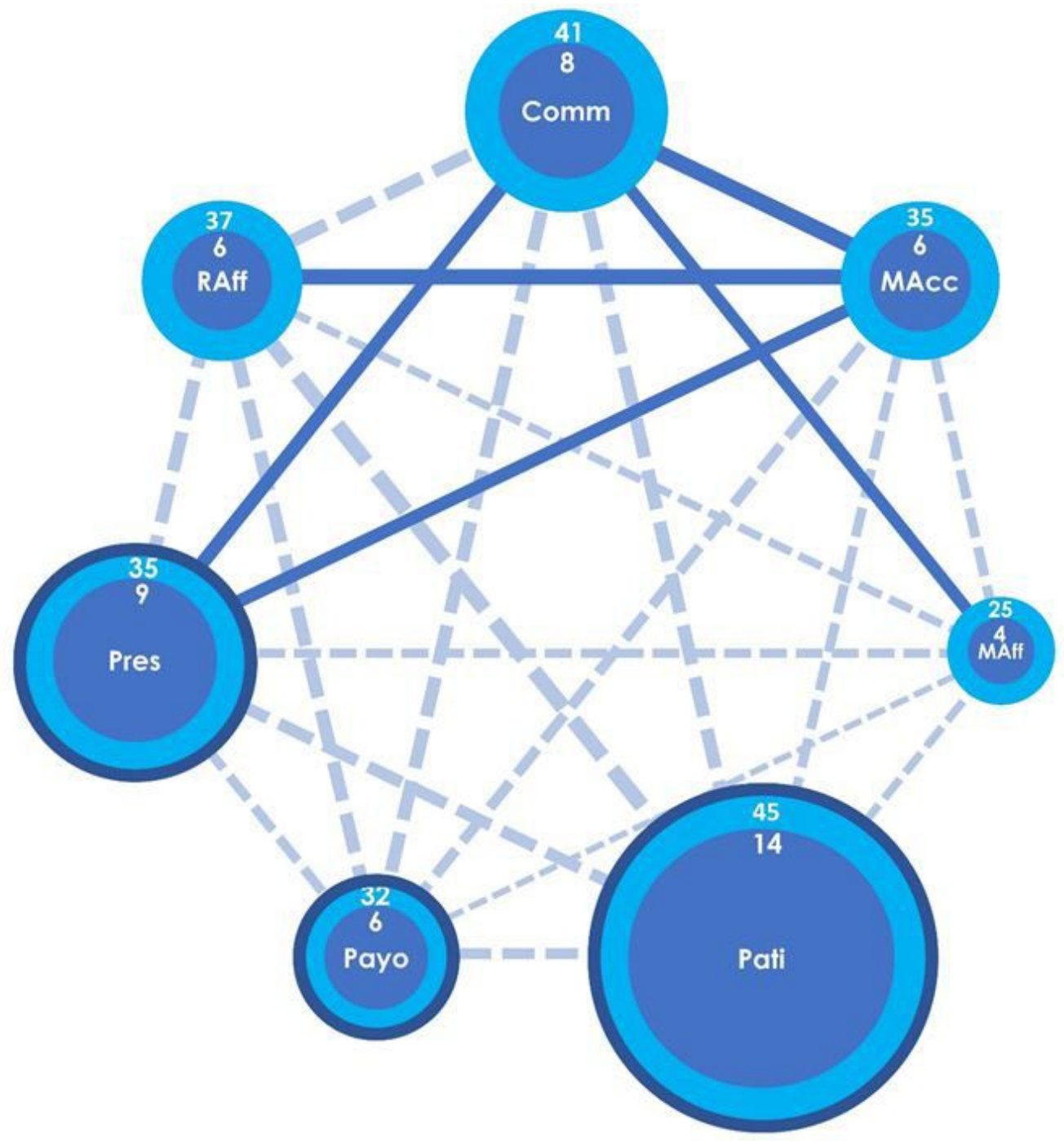

Total number of items per stakeholder group

Total number of unique items per stakeholder group $(\mathrm{PH}+)$

Total number of unique items per stakeholder group (PH-)

Homogeneity in consensus on common items $\mathrm{P}<0.05$ where line thickness indicates the relative number of common items agreed upon by stakeholders

Heterogeneity in consensus on common items $\mathrm{P}>0.05$ where line thickness indicates the relative number of common items raised by stakeholders

\section{Figure 1}

Pairwise degree of consensus and heterogeneity of quality indicators constituting a rare disease patient registry. Comm (Commercial); MAcc (Market Access); MAff (Medical Affairs); RAff (Regulatory Affairs); Pati (Patients); Payo (Payors); Pres (Prescribers) 


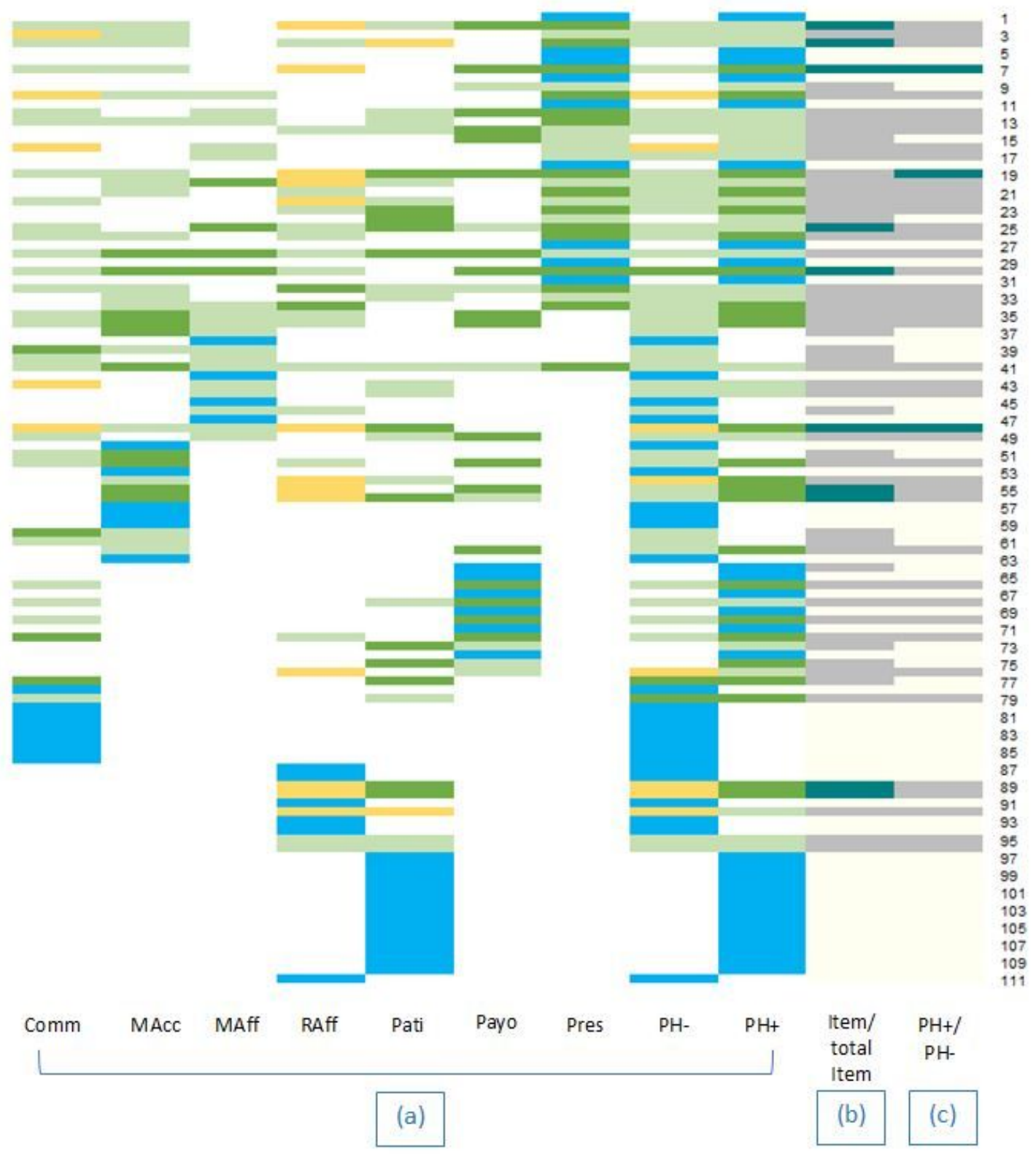

\begin{tabular}{|c|c|}
\hline Not Suggested & Unique to Stakeholder Group \\
\hline Complete Consensus $(\mathrm{Cl}=1.00)$ & Homogeneous for Consensus \\
\hline Consensus $(0.50<\mathrm{Cl})$ & Heterogeneous for Consensus \\
\hline Consensus $(0<\mathrm{Cl} \leq 0.50)$ & $\begin{array}{l}\text { (Non-Pharma); Comm (Commercial); Macc (Market } \\
\text { tical Affairs); Raff (Regulatory Affairs); Pres (Prescribers); } \\
\text { o (Payor) }\end{array}$ \\
\hline
\end{tabular}

\section{Figure 2}

Distribution of suggested items listed in item numbering ascending order. (a) stakeholder: uniqueness, consensus index; (b) heterogeneity of items by level of stakeholder consensus; (c) heterogeneity by Pharma $(\mathrm{PH}+)$ or Non-Pharma $(\mathrm{PH}-)$ stakeholder group consensus threshold for inclusion $(\mathrm{Cl} \geq 0.05)$ within their discipline listed in item numbering ascending order. 


\section{Supplementary Files}

This is a list of supplementary files associated with this preprint. Click to download.

- SupplementaryInformation2NonPharmaStakeholders.docx

- SupplementaryInformation1PharmaStakeholders.docx 